\title{
Efektivitas Knowledge Sharing dalam Meningkatkan Kesiapan Kerja
}

\section{Effectiveness of Knowledge Sharing to Enhances the Work Readiness}

\author{
Laili Qomariyah(1)*, Aning Az-zahra(2) \\ Fakultas Psikologi dan Humaniora, Universitas Muhammadiyah Magelang, Indonesia
}

Diterima : 24 Juli 2020; Disetujui : 29 Juli 2020; Dipublish : 29 Agustus 2020

*Corresponding author: E-mail: laili.qomariyah@ummgl.ac.id

\begin{abstract}
Abstrak
Penelitian ini bertujuan untuk melihat efektivitas knowledge sharing dalam meningkatkan kesiapan kerja siswa. Metode yang digunakan adalah pre eksperimen dengan one group pretest posttest. Dilakukan dengan melalui 2 tahap, yaitu pertama tahap uji validitas dan reliabilitas skala yang telah diadaptasi. Hasil validitas dan reliabilitas menunjukkan bahwa 27 aitem memiliki nilai $\mathrm{r}_{\mathrm{xy}}$ antara 0,831 - 0,388 dan nilai signifikansi disetiap aitem berada pada rentang 0,000 - 0,012. Berdasarkan nilai $r$ tabel $(95 \%), n=41$ adalah 0,308 maka skala tersebut dinyatakan valid (nilai $r$ tabel $<\mathrm{r}$ hitung). Hasil uji reliabilitas memiliki nilai cronbach alpha sebesar 0,956 yang berarti seluruh aitem reliabel. Tahap kedua adalah pemberian perlakuan dengan urutan memberikan pretest terlebih dahulu, pemberian perlakuan, dan posttest. Hasil uji normalitas menunjukkan bahwa data tersebut adalah normal dengan ditunjukkan nilai signifikansi baik pretest maupun posttest masing-masing sebesar $0,200(>0,05)$. Uji hipotesis menggunakan $T$ test related samples dan menghasilkan nilai korelasi sebesar 0,909 dengan nilai signifikansi 0,00. Hal ini menunjukkan bahwa antara pretest maupun posttest memiliki korelasi yang sangat kuat $(\mathrm{p}<0,05)$. Sedangkan hasil paired test menunjukkan nilai t sebesar -2,288 (>1,96; taraf signifikansi 95\%) dengan nilai singnifikansi sebesar $0,025(\mathrm{p}<0,05)$ sehingga membuktikan bahwa terdapat perbedaan kesiapan kerja antara sebelum diberikan perlakuan dengan sesudah diberikan perlakuan.
\end{abstract}

Kata Kunci: Knowledge sharing; Efektivitas, Kesiapan Kerja

\begin{abstract}
This study aims to see the effectiveness of knowledge sharing toward work readiness. The method used pre experiment with one group pretest posttest. Method of this study trough 2 stages, the first stage is validity and reliability test. The results shows that $r_{x y}$ value between $0.831-0.388$ and the significance value in each item is range of 0,000 - 0.012. Based on the value of $r$ table (95\%), $n=41$ is 0.308 , scale is valid ( $r$ table value $<r$ count). The reliability test results Cronbach alpha value 0.956 which means that all items are reliable. The second stage is giving treatment with pretest, treatment, and posttest. The results of the normality test shows that the data are normal with a significance value of both pretest and posttest each indicated by 0.200 (> 0.05). Hypothesis testing uses $T$ test related samples with correlation value 0.909 and significance value of 0.00 . This result shows that between pretest and posttest had a very strong correlation $(p<0.05)$. Results of paired test shows that $t$ value -2.288 ( $>1.96$; 95\%) with a significance value of $0.025(p<0.05)$. That data prove that there were difference of work readiness before and after treated.
\end{abstract}

Keywords: Knowledge sharing; Effectiveness; Work Readiness

Rekomendasi mensitasi :

Qomariyah, L., \& Az-zahra, A. (2020), Efektivitas Knowledge Sharing dalam Meningkatkan Kesiapan Kerja. Jurnal Penelitian Pendidikan, Psikologi dan Kesehatan (J-P3K), 1 (2): 92-99. 


\section{PENDAHULUAN}

Kemajuan teknologi yang terus bergerak saat ini memiliki dampak yang bermacam-macam di berbagai ranah kehidupan manusia. Dampak tersebut dapat berupa dampak positif dengan membuat pekerjaan manusia lebih cepat, akurat, dan tersimpan dengan baik sebagai dampak yang positif, namun selain itu kemajuan teknologi juga memberikan dampak yang negatif. Salah satu dampak negatif yang dimaksud adalah banyaknya posisi pekerjaan yang digantikan oleh sebuah mesin maupun sistem (Lemaignan, Warnier, Sisbot, Clodic, \& Alami, 2017) .

Hal tersebut merupakan sebuah tantangan besar yang harus disikapi dengan cepat dan tepat agar manusia tidak kehilangan posisinya di dunia kerja. Kondisi tersebut semakin menjadi tak terbayangkan saat tahun 2030 merupakan puncak dari bonus demografi di Indonesia khususnya di usia produktif (http://www.bps.go.id). Kondisi ini sebenarnya akan memberikan dampak yang sangat positif bagi Indonesia karena usia produktif adalah usia emas yang akan dapat memberikan dampak pada peningkatan kesejahteraan dan kemajuan Indonesia.

Negara Indonesia diprediksi akan menjadi kekuatan ekonomi global ke 4 jika kita dapat memanfaatkan kondisi emas ini (http://www.kominfo.go.id). Kekuatan tersebut harus didukung dan ditunjang oleh kualitas sumber daya manusia (SDM) yang baik. SDM harus mampu menjawab tantangan di dunia kerja dengan baik. Selain itu, adanya Masyarakat Ekonomi Asean (MEA) yang dibentuk tahun 2015 telah membuat kondisi perindustrian, perdagangan, investasi, jasa dan transportasi, telekomunikasi, pariwisata, serta keuangan di Indonesia menjadi lebih dinamis.

MEA merupakan upaya integratif dan berkemajuan dari negara ASEAN termasuk Indonesia didalamnya untuk membentuk wawasan masyarakat yang lebih maju, hidup dalam lingkungan yang damai, stabil, dan makmur, yang dipersatukan oleh hubungan kemitraan secara dinamis serta menciptakan masyarakat yang saling peduli (http://www.kemlu.go.id).

Akan tetapi sangat disayangkan adanya bonus demografi dan MEA saat ini belum dapat membawa dampak yang nyata bagi kemajuan Indonesia. Banyaknya kesempatan bekerja belum cukup mampu menyerap tenaga produktif Indonesia. BPS mencatat bahwa 194.779.441 penduduk produktif yang ada di Indonesia (15 tahun keatas) dan hanya 124.004 .950 penduduk produktif yaitu 63\% yang terserap di dunia kerja. Menurut Chavan dan Carter (2018) bahwa Tingginya permintaan tenaga kerja tidak akan terpenuhi jika kualitas dari SDM belum sesuai dengan standar kerja yang diinginkan sebuah perusahaan dan industri.

Caballero dan Walker (2010) menyatakan bahwa diperlukan kesiapan kerja bagi para lulusan untuk dapat direkrut sebuah perusahaan menjadi seorang karyawan. Kesiapan kerja dapat digunakan sebagai informasi dalam memprediksi seseorang mengenai potensinya untuk melihat kinerja dan karirnya pada masa depan (Caballero \& Walker, 2010). 
Kesiapan kerja berkaitan dengan sejauh mana individu dianggap memiliki pengetahuan dan keterampilan untuk bekerja secara mandiri sesuai dengan tuntutan ditempat kerja (Verma, Sanjeev, \& Alan, 2019). Selain itu kesiapan kerja berkaitan dengan kompetensi yaitu meliputi pengetahuan, keterampilan, dan kepribadian individu di tempat kerja (Spencer \& Spencer, 1993). Paradigma di Indonesia masih meyakini bahwa keunggulan akademis masih menjadi faktor paling penting dalam menentukan masa depan mereka. Hal inilah yang menjadi salah satu faktor dari adanya permasalahan tidak terserapnya tenaga kerja Indonesia.

Salah satu yang bisa dilakukan untuk membentuk lulusan akademik menjadi individu dengan kesiapan kerja yang baik dibutuhkan adanya pengetahuan, pembiasaan, dan evaluasi (Cripe \& Mansfield, 2002). Hal pertama adalah dengan adanya pemberian pengetahuan mengenai kompetensi yang mampu meningkatkan kesiapan kerja para lulusan dengan melakukan knowledge sharing. Ahmad dan Karim (2019) menjelaskan bahwa knowledge sharing mampu memberikan dampak positif terhadap organisasi dengan berbagai cara. Selain itu knowledge sharing juga dapat memberikan perubahan perilaku terhadap individu (Ahmad \& Karim, 2019; Lee, 2018).

Knowledge sharing merupakan sebuah proses pertukaran informasi yang berkaitan dengan tugas, saran, dan keahlian untuk membantu individu dan berkolaborasi dengan individu lainnya untuk melakukan tugas sehari-hari, menyelesaikan masalah, dan memunculkan ide-ide baru (Ahmad, 2018). Sarana untuk melakukan knowledge sharing adalah bahasa, sehingga keterbatasan bahasa yang digunakan dapat mempengaruhi kualitas dari knowledge sharing yang diterima oleh peserta (Ahmad, 2018). Pendapat yang sama dikemukakan oleh Lee (2018) bahwa kualitas knowledge sharing yang diterima mampu memberikan dampak pada tingkat kreativitas seseorang, namun intensitas dari pemberian knowledge sharing tidak mampu memberikan dampak pada tingkat kreativitas individu.

Ahmad dan Karim (2019) menyatakan bahwa knowledge sharing mampu memberikan dampak pada individu, kelompok, maupun organisasi. Lebih detail Masa'deh, Obeidat, dan Tarhini (2016) menjelaskan bahwa knowledge sharing dari seorang pemimpin mampu meningkatkan kinerja karyawan dan secara tidak langsung mampu meningkatkan kinerja perusahaan.

Berdasarkan penelitian yang sudah ada, masih sedikit pembahasan mengenai knowledge sharing yang berkaitan dengan ketrampilan individu yang bertujuan untuk mempersiapkan individu dalam memasuki dunia kerja dan berada diluar area organisasi. Saat ini knowledge sharing dilakukan oleh organisasi untuk meningkatkan pengetahuan anggota organisasinya yang merupakan bagian dari knowlege management.

Berdasarkan latar belakang tersebut, peneliti melihat bahwa sangat penting bagi peneliti sebagai bagian dari civitas akademika untuk terus 
melakukan upaya pengembangan kualitas SDM khususnya dalam ranah psikologi industri dan organisasi. Hal ini dimaksudkan agar keilmuan psikologi khususnya psikologi industri dan organisasi terus dapat berkembang dan bermanfaat dalam upaya perbaikan kualitas SDM di Indonesia.

Penelitian ini bertujuan untuk mengetahui efektivitas knowledge sharing mengenai kesiapan kerja bagi siswa SMK yang akan menapaki dunia kerja agar siswa SMK lebih siap dalam menghadapi tantangan dunia kerja saat ini.

Latar belakang tersebut menguatkan peneliti untuk melakukan penelitian dengan hipotesis bahwa knowledge sharing efektif untuk meningkatkan kesiapan kerja siswa SMK.

\section{METODE PENELITIAN}

Penelitian ini dilakukan dengan 2 tahapan, yaitu tahap 1 untuk uji coba skala dan tahap 2 untuk menguji hipotesis penelitian. Berikut adalah gambar dari setiap tahapan:

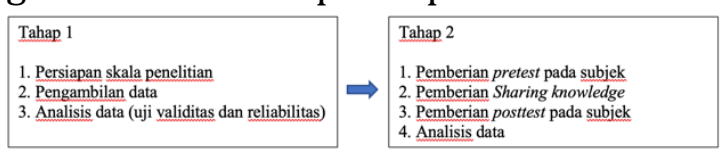

Gambar 1. Metode Penelitian

Sumber: Data internal peneliti

Tahap 1

Tahap pertama merupakan bagian dari penelitian untuk menguji skala yang akan digunakan dalam penelitian. Skala yang digunakan merupakan skala kesiapan kerja yang diadaptasi dari Savickas career construction theory. Skala kesiapan kerja memiliki 4 dimensi, yaitu: 1) career concern yang terdiri dari 9 aitem, 2) career control terdiri dari 7 aitem, 3) career coriousity terdiri dari 8 aitem, dan 4) career confidence terdiri dari 10 aitem.

Subjek Penelitian Tahap 1

Subjek yang digunakan dalam tahap penelitian ini memiliki kriteria yaitu sebagai siswa kelas 12 Madrasah Aliyah Negeri (MAN) 1 Kabupaten Magelang yang diambil dengan metode random sampling. Alasan pengambilan subjek tersebut dikarenakan di MAN 1 Kabupaten Magelang seluruh siswa dibekali dengan ketrampilan khusus yang meliputi tataboga, menjahit, otomotif, listrik, dan teknik komputer jaringan dengan tujuan untuk membekali siswa dalam memasuki dunia kerja setelah mereka lulus. Selain itu, kelas 3 diasumsikan jenjang yang telah memiliki kesiapan kerja paling baik dibandingkan dengan jenjang 1 dan 2 karena ketrampilan dan wawasan yang mereka dapatkan jauh lebih banyak dibanding dengan jenjang dibawahnya.

Teknik Analisis Data Tahap 1

Analisis data uji coba dimaksudkan untuk menguji validitas dan reliabilitas skala yang akan digunakan untuk penelitian. Uji validitas dilakukan dengan menggunakan pearson product moment. Uji reliabilitas dari skala tersebut dilakukan dengan analisis alpha cronbach dimana kedua uji tersebut dilakukan dengan bantuan SPSS.

Tahap 2

Tahap 2 dilakukan untuk menguji efektivitas dari knowledge sharing dalam meningkatkan kesiapan kerja bagi siswa yang diproyeksikan untuk mampu bekerja setelah lulus.

Prosedur Tahap 2 
Berikut ini adalah prosedur dalam melaksanakan penelitian ini, yaitu: 1) sebelum pemberian sharing knowledge dilakukan, subjek diberikan skala kesiapan kerja yang telah di uji validitas dan reliabilitasnya sebagai pretest, 2) diberikan sesi sharing knowledge mengenai kesiapan individu dalam mencari pekerjaan oleh pemateri yang memiliki kriteria sebagai psikolog industri dan organisasi, 3) diberikan waktu untuk tanya jawab antara peserta dan pemateri sehingga proses transfer knowledge bisa lebih maksimal, dan 4) pemberian posttest kepada subjek.

Subjek Penelitian Tahap 2

Subjek penelitian pada tahap 2 adalah SMKN 1 Ngablak Kabupaten Magelang dengan alasan karena lulusan SMKN 1 Ngablak diproyeksikan untuk bekerja setelah lulus. Subjek berjumlah 75 orang dari berbagai jurusan, yaitu peternakan, pertanian, dan pemasaran. Subjek berasal dari kelas 12 karena diasumsikan pada kelas tersebut mereka akan lebih membutuhkan pengetahuan dan wawasan lebih banyak mengenai bagaimana kesiapan dalam mencari sebuah pekerjaan.

Teknik Analisis DataTahap 2

Analisis data dilakukan dengan menggunakan $T$ test relates samples yaitu teknik analisis untuk membandingan sebuah variabel bebas yang dilakukan dengan bantuan SPSS.

\section{HASIL DAN PEMBAHASAN}

Penelitian tahap 1 dilakukan dengan menyebarkan 60 kuesioner kepada subjek untuk diisi pada tanggal 710 Desember 2019 dan yang telah kembali kepada peneliti sejumlah 50 kuesioner. Setelah dilakukan screening dan pengecekan data, hanya 41 kuesioner yang datanya dapat digunakan dan diolah. Tahap 2 dilakukan dengan menggunakan subjek yang berbeda dengan tahap 1 . Subjek pada tahap 2 berjumlah 75 siswa yang kemudian dilakukan screening data pretest dan posttest dan terdapat 7 subjek yang datanya tidak dapat dianalisis, sehingga total subjek pada tahap 2 adalah 68 siswa.

Hasil dari analisis data yang telah dilakukan oleh peneliti adalah sebagai berikut:

Tahap 1

Keseluruhan dari aitem kesiapan kerja adalah valid dan dapat digunakan dalam pengambilan data penelitian karena uji validitas menghasilkan nilai signifikansi berada pada kontinum 0,000,012 dengan nilai $r_{x y}$ pada kontinum 0,831-0,388 (nilai $r$ tabel dengan taraf signifikansi $5 \%$ dan $n=41$ adalah sebesar 0,308).

Tabel 1. Reliabilitas aitem

\begin{tabular}{lll}
\hline $\begin{array}{l}\text { Cronbach } \\
\text { Alpha }\end{array}$ & $\Sigma$ Aitem & Keterangan \\
\hline 0,956 & 27 & Reliabel \\
\hline
\end{tabular}

Sumber Tabel: Olah data peneliti

Tabel 1 menunjukkan bahwa jumlah aitem pada skala kesiapan kerja adalah 27 aitem dengan nilai cronbach alpha sebesar 0,956. Hasil ini menunjukkan bahwa nilai cronbach alpha $>0,60$ yang memiliki makna bahwa skala tersebut reliabel untuk digunakan dalam pengambiland ata penelitian. 
Tahap 2

Tahap 2 merupakan tahap pelaksanaan perlakuan penelitian eksperimen. Sebelum data dianalisis dengan menggunakan $T$ test relates samples maka syarat yang harus terpenuhi adalah data yang didapat harus terdistribusi normal. Peneliti menggunakan kolmogorov smirnov dengan bantuan SPSS untuk menguji normalitas data penelitian. berikut ini adalah hasil dari uji normalitas data penelitian:

Tabel 2. Uji normalitas data

\begin{tabular}{lll}
\hline Data & Sig. & Keterangan \\
\hline Pretest & 0,200 & Normal \\
\hline Posttest & 0,200 & Normal \\
\hline
\end{tabular}

Sumber Tabel: Olah data peneliti

Tabel 2 menunjukkan bahwa data penelitian baik pretest dan posttest memiliki data yang terdistribusi normal karena nilai signifikansi dari masingmasing data $>0,05$. Hal ini menunjukkan bahwa syarat data yang akan dilakukan uji $T$ test relates samples sebagai data yang normal terpenuhi.

Tabel 3. Paired samples correlations

\begin{tabular}{lll}
\hline Pair & Correlations & Sig. \\
\hline $\begin{array}{l}\text { Pretest dan } \\
\text { posttest }\end{array}$ & 0,909 & 0,00
\end{tabular}

Sumber Tabel: Olah data peneliti

Tabel 3 menunjukkan bahwa antara pretest dan posttest memiliki hubungan yang kuat yang ditunjukkan dengan nilai korelasi sebesar 0,909 dan nilai signifikansi sebesar 0,00.

Tabel 4. T Paired test

\begin{tabular}{llll}
\hline & $\mathrm{t}$ & $\mathrm{df}$ & Sig. \\
\hline $\begin{array}{l}\text { Pretest } \\
\text { posttest }\end{array}$ & $-2,288$ & 67 & 0,025 \\
\hline
\end{tabular}

Tabel 4 menunjukkan bahwa nilai $\mathrm{t}$ sebesar $-2,288>1,96$ yaitu angka kritis pada taraf signifikansi 95\%. Selain itu juga bisa dilihat bahwa nilai singnifikansi sebesar 0,025, yaitu lebih kecil dari 0,05 $(p<0,05)$ sehingga data tersebut membuktikan bahwa terdapat perbedaan pengetahuan (knowledge) antara sebelum diberikan perlakuan knowledge sharing dengan sesudah diberikan perlakuan.

Hasil tersebut menunjukkan bahwa knowledge sharing mampu meningkatkan kesiapan kerja lulusan SMK yang akan memasuki dunia kerja. Kesiapan kerja perlu dibentuk sejak siswa masih di dunia pendidikan agar kesiapan kerja yang dimiliki siswa tidak hanya sebatas pengetahuan namun juga sebuah keterampilan dan sifat yang diterapkan melalui sebuah pembiasaan (Spencer, L \& Spencer, S, 1993).

Knowledge sharing di dunia pendidikan mampu meningkatkan kesiapan kerja siswa SMK dikarenakan siswa benar-benar bisa mendapatkan apa yang mereka butuhkan dalam bekal memasuki dunia kerja. Siswa tidak hanya memahami mengenai pengetahuan akademis yang sifatnya teoritis saja namun juga mendapatkan pengetahuan baru yang sifatnya tacit knowledge yang tidak mereka dapatkan selama duduk di bangku sekolah (Lee, 2018).

Tacit knowledge didalam knowlede sharing mampu memberi gambaran nyata mengenai dunia kerja dan apa yang harus siswa lakukan saat sudah memasuki dunia kerja (Mohajan \& Mohajan, 2016; Paulin \& Suneson, 2011).Siswa menjadi tahu mengenai apa yang harus dilakukan, apa yang harus 
ditingkatkan dalam dirinya agar menjadi pekerja yang kompetitif, dan apa yang harus dihindari. Semua itu bisa siswa dapatkan saat knowledge sharing.

Komunikasi 2 arah di dalam knowledge sharing juga mampu menjadi faktor dalam meningkatkan kesiapan kerja siswa SMK. Hal ini dikarenakan siswa dapat memperdalam pengetahuan dan keterampilan yang mereka rasa belum mendalam sesuai dengan tinggi rendahnya pengetahuan dan keterampilan masing-masing individu (Mohajan \& Mohajan, 2016).

Sesuai dengan teori Albert Bandura mengenai belajar sosial bahwa perilaku yang muncul karena adanya interaksi dari lingkungan, perilaku itu sendiri, dan proses berfikir dari setiap individu. Adanya knowledge sharing menjadi jembatan antara siswa dengan lingkungan luarnya yaitu lingkungan kerja yang merupakan lingkungan eksternal dari lingkungan pendidikan yang siswa miliki, mendorong siswa untuk melakukan proses berfikir, dan akan saling mempengaruhi kedua faktor tersebut dengan sikap individu dan efikasi diri yang ada didalamnya (Bandura, 2020).

Penelitian yang telah dilakukan oleh Tentama dan Merdiaty (2019) juga membuktikan bahwa efikasi diri individu dapat mempengaruhi mengenai bagaimana kesiapan kerja mereka. Efikasi diri mampu membuat individu menjadi memiliki keyakinan atas apa yang akan dilakukannya berkaitan dengan kesiapan kerja yang mereka miliki.

\section{SIMPULAN}

Hasil uji analisis menunjukkan bahwa knowledge sharing mampu meningkatkan kompetensi kesiapan kerja siswa SMK kelas 12. Hasil ini sekaligus mengkonfirmasi bahwa knowledge sharing mampu digunakan sebagai cara dalam meningkatkan kompetensi individu (Ahmad, 2018). Perbedaan hasil penelitian ini dengan penelitian sebelumnya adalah dalam hal situasi.

Hasil penelitian ini menunjukkan bahwa knowledge sharing juga efektif diterapkan di dunia pendidikan dan tidak hanya sebagai bagian dari knowledge management di sebuah perusahaan. Adanya perbedaan setting penggunaan knowledge sharing (dunia pendidikan dan dunia kerja) akan berdampak juga terhadap adanya knowledge barrier yang berbeda antara setting dunia pendidikan dan dunia kerja. Hal ini bisa menjadi masukan bagi peneliti selanjutnya untuk bisa menemukan knowledge barrier di setting dunia pendidikan.

Saran berdasarkan hasil penelitian ini yang menyatakan bahwa terdapat pengaruh knowledge sharing terhadap kesiapan kerja siswa SMK dapat digunakan sebagai acuan bagi pihak sekolah terutama SMK yang memiliki visi misi dapat mencetak para siswa yang berkualitas dan dapat terserap di dunia kerja dengan maksimal setelah mereka lulus.

Saran bagi peneliti selanjutnya yang memiliki ketertarikan dan fokus topik yang sama dengan peneliti untuk bisa mengembangan penelitian ini dengan melakukan eksperimen dengan kelompok kontrol agar bisa dipastikan 
peningkatan kesiapan kerja dari kelompok eksperimen yang memiliki kemungkinan ikut berpengaruh terhadap terbentuknya variabel dependen yaitu kesiapan kerja.

\section{UCAPAN TERIMAKASIH}

Terima kasih peneliti sampaikan kepada Universitas Muhammadiyah Magelang atas pendanaan penelitian melalui program PRVI.

\section{DAFTAR PUSTAKA}

Ahmad, F. (2018). Knowledge sharing in a nonnative language context: Challenges and strategies. Journal of Information Science, 44(2), 248-264. https://doi.org/10.1177/0165551516683607

Ahmad, F., \& Karim, M. (2019). Impacts of knowledge sharing: a review and directions for future research. Journal of Workplace Learning, 31(3), 207-230. https://doi.org/10.1108/JWL-07-2018-0096

Bandura, A. (2020). Social Learning Theory. United States of America: Prentice Hall International (UK).

Caballero, C. L., \& Walker, A. (2010). Work readiness in graduate recruitment and selection: A review of current assessment methods. Journal of Teaching and Learning for Graduate Employability, 1(1), 13.

https://doi.org/10.21153/jtlge2o1ovolınoiart 546

Chavan, M., \& Carter, L. (2018). Management students - expectations and perceptions on work readiness. International Journal of Educational Management, 32(5), 82585o. https://doi.org/10.1108/IJEM-10-20160219

Cripe, E. J., \& Mansfield, R. S. (2002). Value added Competencies (2nd ed.) Butterworth Heinemann.

https://www.bps.go.id/publication/2012/11/30/4c 36afac847c656d4db93040/analisisstatistik-sosial--bonus-demografi-danpertumbuhan-ekonomi-.html, diakses tanggal 13 Juni 2020

https://kemlu.go.id/portal/id/read/113/halaman_ list_lainnya/masyarakat-ekonomi-aseanmea, diakses tanggal 13 Juni 2020
Lee, J. (2018). The Effects of Knowledge Sharing on Individual Creativity in Higher Education Institutions: Socio-Technical View. Administrative Sciences, 8(2), 21. https://doi.org/10.3390/admsci8020021

Lemaignan, S., Warnier, M., Sisbot, E. A., Clodic, A., \& Alami, R. (2017). Artificial cognition for social human-robot interaction: An implementation. Artificial Intelligence. https://doi.org/10.1016/j.artint.2016.07.002

Masa'deh, R., Obeidat, B. Y., \& Tarhini, A. (2016). A Jordanian empirical study of the associations among transformational leadership, transactional leadership, knowledge sharing, job performance, and firm performance: A structural equation modelling approach. Journal of Management Development, 35(5), 681-705. https://doi.org/10.1108/JMD-09-2015-0134

Mohajan, H., \& Mohajan, H. K. (2016). Sharing of Tacit Knowledge in Organizations: A Review Sharing of Tacit Knowledge in Organizations: A Review. American Journal of Computer Science and Engineering, 3(2), 6-19.

Paulin, D., \& Suneson, K. (2011). Knowledge transfer, knowledge sharing and knowledge barriers-three blurry terms in KM. Proceedings of the European Conference on Knowledge Management, ECKM, 2(1), 752-760.

Spencer, L, M., \& Spencer, S, M. (1993). Models for superior performance. New York: Wiley. 384.

Tentama, F., \& Merdiaty, N. (2019). Self-Efficacy and Work Readiness among Vocational High School Students. 13(2), 277-281. https://doi.org/10.11591/edulearn.v13i2.126 77

Verma, P., Sanjeev, K., \& Alan, N. (2019). Workreadiness integrated competence model: Conceptualisation and scale development. Education + Training, 61(5), 568-589. https://doi.org/10.1108/ET-o5-2018-0114 